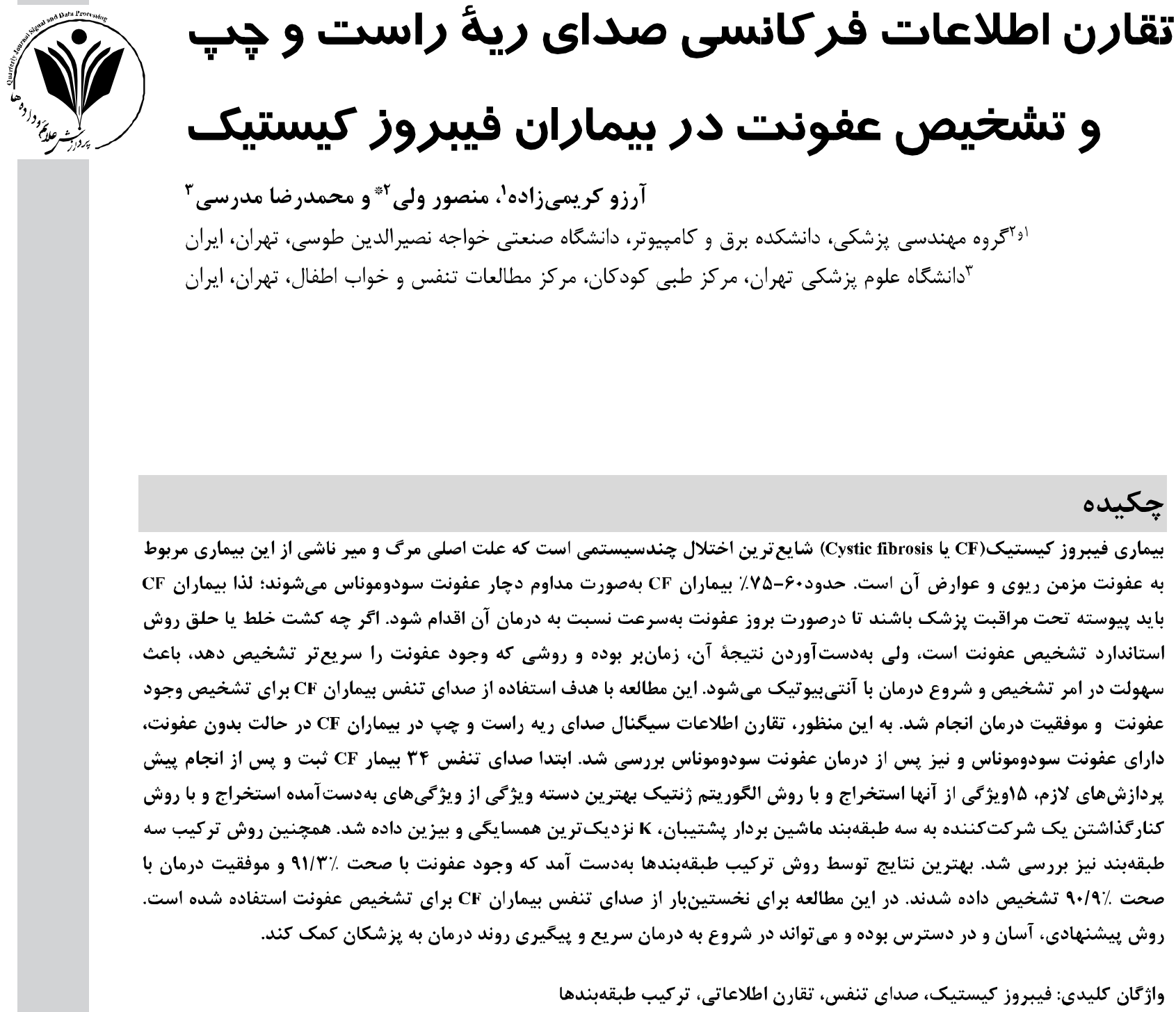

\title{
Symmetry of Frequency information in Right and Left Lung sound and Infection Detection in Cystic Fibrosis Patients
}

\author{
Arezoo Karimizadeh ${ }^{1}$, Mansour Vali $^{2 *}$ \& Mohammadreza Modaresi ${ }^{3}$ \\ 1,2 Department of Biomedical Engineering, K. N. Toosi University of Technology, Tehran, Iran \\ ${ }^{3}$ Pediatric Respiratory and Sleep Medicine Research Center, Children's Medical Center, Tehran \\ University of Medical Sciences, Tehran, Iran
}

\begin{abstract}
Cystic fibrosis (CF) is the most common autosomal recessive disorder in white skinned individuals. Chronic lung infection is the main cause of mortality in this disease. Approximately $60-75 \%$ of adult CF patients frequently suffer from Pseudomonas aeruginosa (PA) infection that is strongly associated with inflammation, lung destruction, and increased mortality. Therefore, CF patients should be followed up by physicians to diagnose infection in the primary stage, start treatment, and reduce the risk of chronic infection. Although sputum culture is the gold standard for diagnosis of PA infections, a rapid and accurate * Corresponding author * نويسندة عهدهدار مكاتبات


diagnostic method can facilitate carly initiation of appropriate therapy and easy monitoring of the condition. The aim of this study was to diagnose CF patients with infection using their lung sound.

In this study, the symmetry of frequency information in right and left lung was investigated in CF patients with positive sputum culture results, negative sputum culture results, and patients who underwent treatment with antibiotics. Respiretorysounds were acquired from 34 CF patients (16 female, 18 male) who were being followed-up at the Pediatric Respiratory and Sleep Medicine Research Center of Children's Medical Center. The patient selection was based on their sputum microbiology culture. The selection category was as follows: 12 patients with normal flora culture results and 11 patients with PA infection. Also, respiratory sounds of 11 patients were recorded one month after antibiotic treatment and they used to investigate the effectiveness of the proposed method.

In the preprocessing step, cardiac sound was removed, respiratory sound cycles were separated and the signals were divided into 64 milisecond frame and 15 features were extracted from each frame. Differences between these features were computed between right and left lungs for early, middle and late section of the respiratory cycle using the new proposed feature. Then, the best group of features was selected by applying Genetic Algorithm. The selected group of features was fed into Support Vector Machine, K Nearest Neighbor and Naïve Bayesian classifier. Also, an Ensemble classifier was examined. The best result was obtained by Ensemble classifier that diagnosed infection by the accuracy of $91.3 \%$ and differentiates a group of CF patients with infection from CF patients who underwent treatment with an accuracy of $90.9 \%$. This study describes a novel method of infection detection in CF patients based only on respiratory sound analysis. The proposed method is a simple and available way for early diagnosis of infection and initiating therapeutic strategies.

Keywords: Cystic Fibrosis, Respiratory Sound, Information Symmetry, Ensemble classifier

$$
\begin{aligned}
& \text { ارتباط زيادى با متورمشدن راههاى هوايى [4]، تخريب ريه و }
\end{aligned}
$$

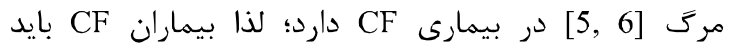

$$
\begin{aligned}
& \text { ييوسته تحت مراقبت يزشك باشند تا در صورت بروز عفونت } \\
& \text { بهسرعت نسبت به درمان آنان اقدام شود. روش استاندارد } \\
& \text { تشخيص بروز عفونت كه در حال حاضر استفاده مىشود، } \\
& \text { كشت خلط يا حلق است. در حال حاضر كشت خلط و حلق دولق } \\
& \text { براى بيماران CF در صورت عدم وجود علامت، بايد هر سه } \\
& \text { ماه يكبار انجام شود؛ ولى در صورت علامتدارشدن بيمارى }
\end{aligned}
$$

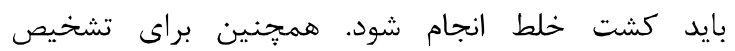

$$
\begin{aligned}
& \text { موفقبودن درمان عفونت، يس از مصرف آنتىبيوتيك نيز }
\end{aligned}
$$

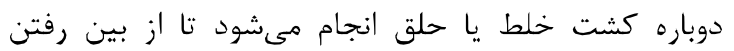

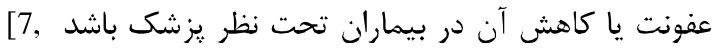

اگر جه كشت خلط يا حلق روش استاندارد تشخيص

عفونت است، ولى بهدستآوردن نتيجه آن زمانبر بوده (بين

سه روز تا يك هفته) و روشى كه وجود عفونت را سريعتر تشخيص دهد، باعث سهولت در امر تشخيص و شروع درمان

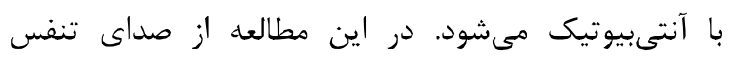
بيماران CF استفاده شده و سعى شده است تا با با روشهاى

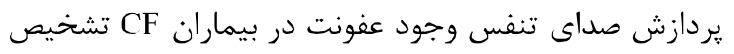

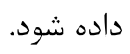

$$
\begin{aligned}
& \text { - } 1 \\
& \text { بيمارى فيبروز كيستيك (Cystic fibrosis يا CF) يك } \\
& \text { اختلال جندسيستمى و شايعترين اختلال اتوزومال' مغلوب } \\
& \text { در سفيد يوستان است كه شيوع آن يك مورد در دوهزار تا تاني } \\
& \text { سههزار تولد زنده در سال است. علت اصلى مرگ و مير ناشى }
\end{aligned}
$$

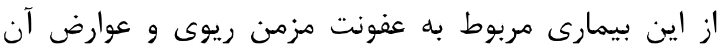

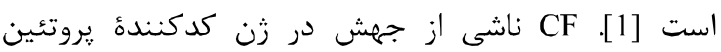

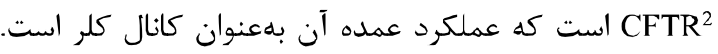

$$
\begin{aligned}
& \text { بنابراين اختلال در اين زن منجر به افزايش جسبند } \\
& \text { ترشح مخاط در راههاى هوايى و دستخاه توارشى اين بيماران } \\
& \text { مىشود. نتايج مطالعهاى كه در سال اوهبا انجام شد، نشان } \\
& \text { داد كه بيمارى فيبروز كيستيك در ايران، از آن جه هيش } \\
& \text { اين تصور مىشد، شايعتر است [2]. }
\end{aligned}
$$

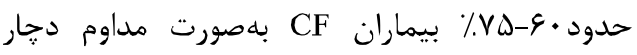

$$
\begin{aligned}
& \text { عفونت سودوموناس مىشوند [3]. عفونت سودوموناس } \\
& \text { ' در اختلال اتوزومى مغلوب، زن جهشيافته مغلوب روى يكى از }
\end{aligned}
$$

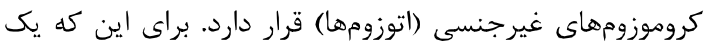

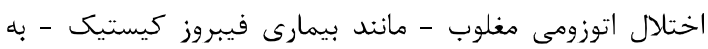

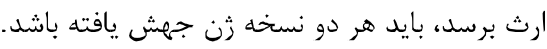

$$
\begin{aligned}
& { }^{2} \text { Cystic fibrosis transmembranc conductive regulator } \\
& { }^{3} \text { Pseudomonas aeruginosa infection }
\end{aligned}
$$


ريه راست و جֶ سودوموناس و پِ ريس از درمان آن متفاوت است.

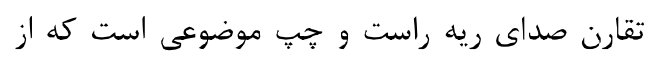

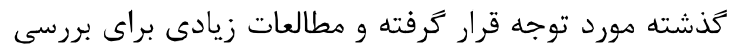
آن انجام شده است. اعتقاد به اينكه صداى ريه راست و جِّ متقارن است، از زمانهاى قديم وجود داشته است. به اين صورت كه يزشكان براى معاينه ريه، صداى ريه راست و جِّ

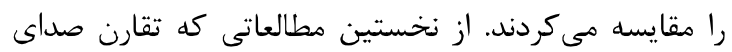
تنفس در ريه راست و جٍِ را بررسى كرد، مطالعهاى بود كه

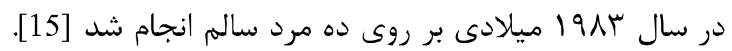

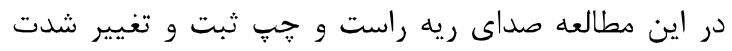
صداى تنفس در قسمتهاى مختلف ريد بررسى شد. نتيجه اين مطالعه نشان داد كه بين محل هاى متقابل در ريه راست

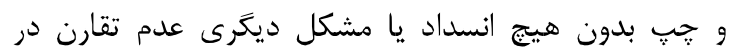
شدت صداهاى ثبت شده وجود دارد. در مطالعه ديخرى كه

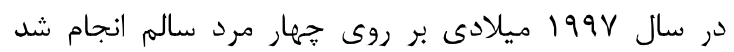

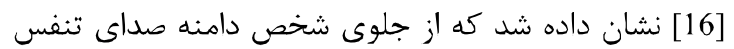

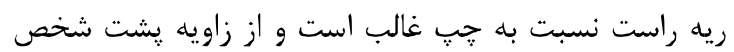

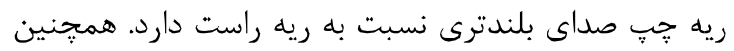

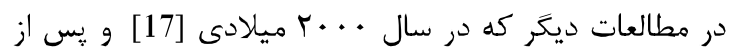

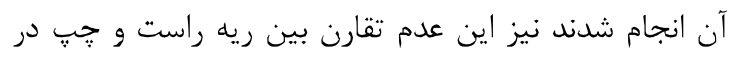
افراد سالم تأييد شده است [18,19].

در حال حاضر تشخيص عفونت در بيماران CF بان

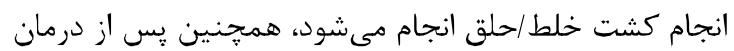

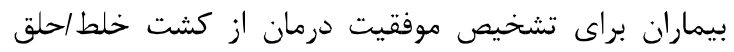
مجدد استفاده مىشود. ثبت صداى تنفس روشى در دسترس

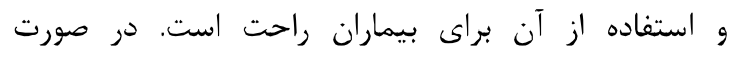
تشخيص عفونت سودوموناس با استفاده از اين روش، مىتوان درمان با آنتىبيوتيك را سريعتر شروع كرد و همجنين موفقبودن درمان بيمار را توسط روش ييشنئهادى تشخيص

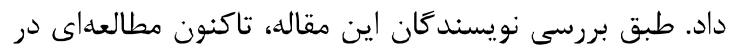
زمينه بررسى صداى تنفس ريه براى تشخيص عفونت سودوموناس در بيماران CF انجام نشده است.

\section{r- شرح دادكان}

براى انجام اين مطالعه صداى تنفس كF بيمار فيبروز كيستيك كه در مركز طبى كودكان تحت نظر بودند ثبت

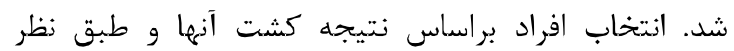
هزشك بود. به اين صورت كه تعداد يازده نفر داراى نتيجه

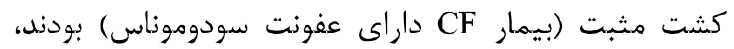

از كارهايى كه تاكنون براى بررسى ارتباط صدا و عفونت انجام شده است، مىتوان به تحليل صداى سرفه براى

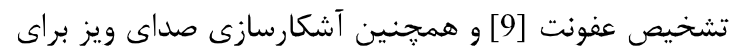
تشخيص عفونت [10] اشاره كرد. در همين اواخر مطالعهاى همئى انجام شده است كه در آن از تحليل زمان فركانسى صداى تنفس ناى كه از دوازده بيمار ثبت شده بود، براى تشخيص است إن افزايش خلط بيماران استفاده كرده است [11]. در مطالعه

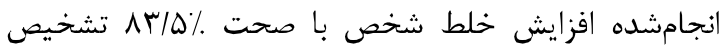

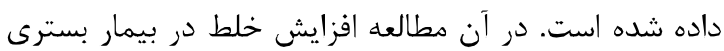
براى اعلام به يرستار جهت انجام عمليات ساكشن بيمار بسترى تشخيص داده شده است. در اين زمينه دطالعات ديگرى نيز انجام شده كه در آنها با استفاده از صداى تنفس است وجود خلط تشخيص داده شده است [12,13] . در [13] با با

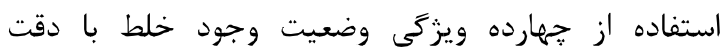

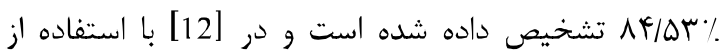

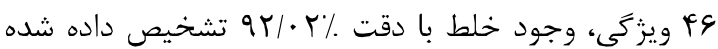
است.

بيماران CF بdدليل اختلال زنتيكى كه دارند، دجار افزايش קُسبندگى و ترشح مخاط در راههاى هوايى و

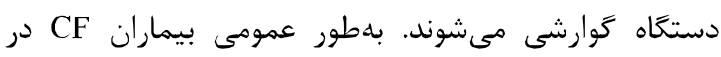
هنخام بروز عفونت سودوموناس افزايش خلط، كاهش عملكرد ريه، افزايش صداى اضافى ريه و افزايش سرفه را تجربه مى كنند [1]. صداهاى تنفس با الگوهاى جريان هوا، تغييرات فشار مربوطه در راههاى هوايى و لرزش بافتهاى ريه ايجاد

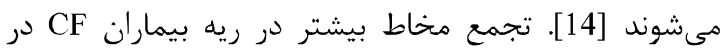
حالت داشتن عفونت سودوموناس باعث تغيير الخوى جريان هواى عبورى و تغيير فشار در راههاى هوايى ريه راست و

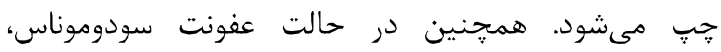
صداهاى اضافى همجون كراكل در ريه شنيده مىشود. از آنجايى كه الخوى منظم و يكسانى براى افزايش مخاط و همجنين دحل صداهاى اضافى ايجادشده در ريه راست و جֶ) انتظار نمىرود، در اين مطالعه فرض شده است كه عدم تقارن مشخصات صداى جٍِ و راست ريه مى رتواند داراى ارتباط با عفونت سودوموناس باشد و مبنائى براى تشخيص عفونت سودوموناس در بيماران CF باشد. بنابراين تقارن اطلاعات سيگنال تنفس ريه راست و جֶٍ در بيمارى CF در

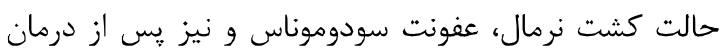
عفونت سودوموناس بررسى شد. اين مطالعه با اين فرض

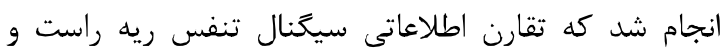

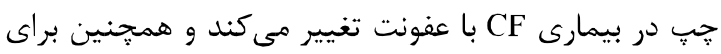


قلب از • لها هرتز كمتر است، از يك فيلتر بالاكَذر با فر كانس قطع • ها هرتز استفاده شد [20]. صداى تنفس بهصورت

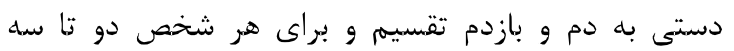

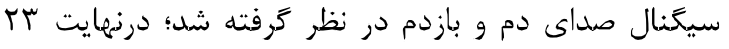

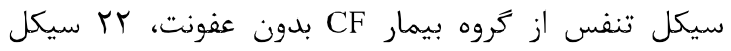
تنفس از گروه بيمار CF داراى عفونت و الب سيكل تنفس از

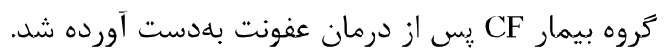
سيكنال صداى تنفس، سيكنال غير ايستا است؛ لذان إنا

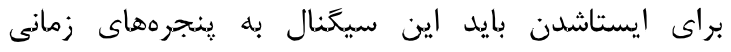

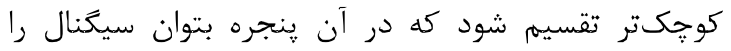

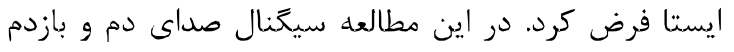

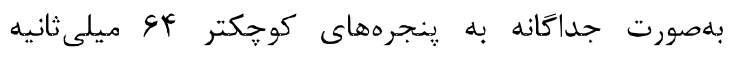

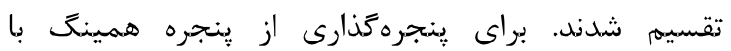

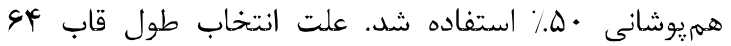

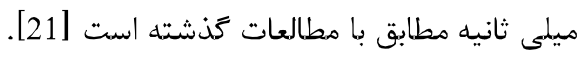

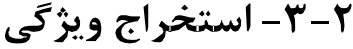

از آنجايى كه هدف اين مطالعه بررسى تقارن اطلاءات

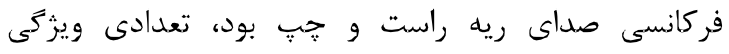

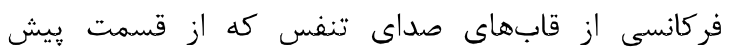

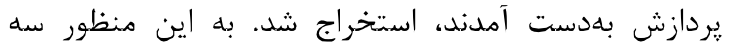

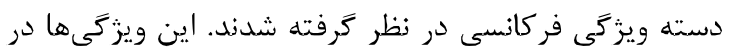
جدول (Г) نشان داده شدهاند.

همانطوركه در جدول (T) مشاهده مىشود، دسته ويثزى نخست مربوط به متوسط دامنه طيف توان سيخنال

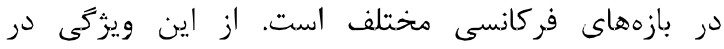

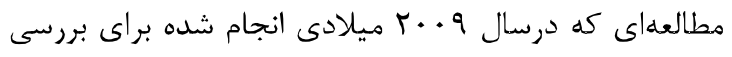
تغيير صداى تنفس ثبتشده از ناى هنغام محدودشدن فلوى تنفسى استفاده شده است [22]. در اين مطالعه جهار دهد باند

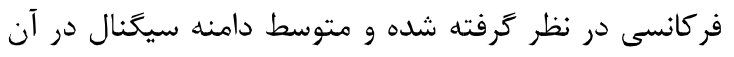

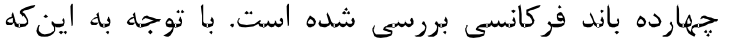

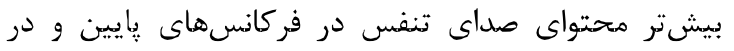
فركانسهاى بالا محتواى فركانسى صداى تنفس كماى كمتر است،

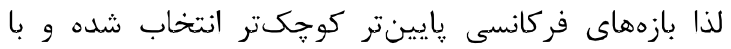

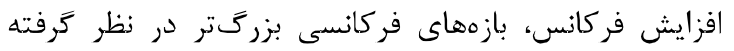
شده است. دسته ويزّى دوم مربوط به صدكهاى فر كانسى است

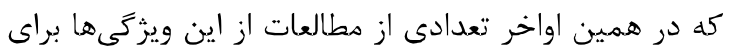

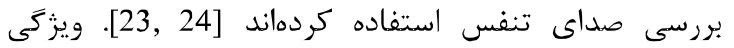
صدك فركانسى، معادل فركانسى است كه درئ در آن، سطح
دوازده نفر نتيجه كشت منفى (بيمار CF بدون عفونت)

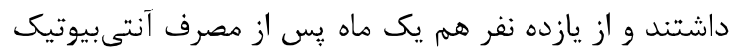

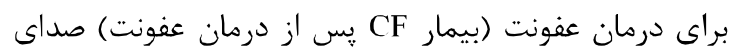

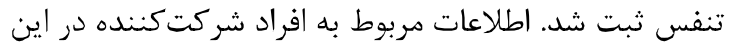

$$
\text { يزوهش در جدول (1) ديده مى شود. }
$$

(جدول-1): اطلاعات افراد شركت كننده در مطالعه (مقادير

بلهورت ميانكين \ انحراف معيار بيان شده است.

(Table-1): participant's information (Values mentioned in

\begin{tabular}{|c|c|c|c|}
\hline در هان & كشت & كشت & تروه \\
\hline $11(6 / 5)$ & $11(4 / 7)$ & $12(6 / 6)$ & تعداد (مرد/زن) \\
\hline $15.7 \pm 5$ & $15.8=5$ & $10.8 \pm 3$ & سن (سال) \\
\hline $42 \pm 13$ & $41 \pm 12$ & $30 \pm 11$ & وزن (كيلوگرم) \\
\hline $152 \pm 12$ & $150 \pm 16$ & $137 \pm 17$ & قد (سانتى متر) \\
\hline
\end{tabular}

ثبت صداى تنفس توسط كوشى يزشكى ديجيتال

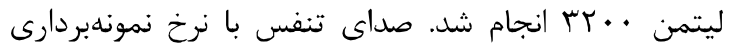

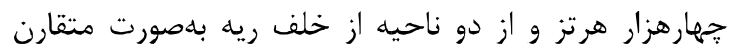
ثبت شد. دحل ثبت صداى تنفس در شكل (1) نشان آن داد داده

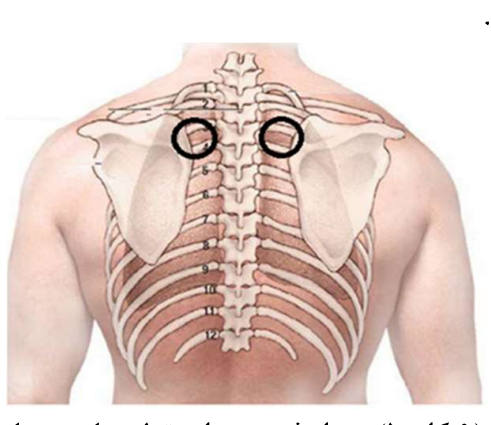

(شكل - ()): محل ثبت صداى تنفس از ريهها

(Figure-1): Regions of the lungs which respiratory sound were recorded from them

صداى تنفس افراد در حالت نشسته ثبت و از افراد

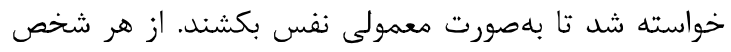
دستكم دو سيكل صداى تنفس ثبت شد.

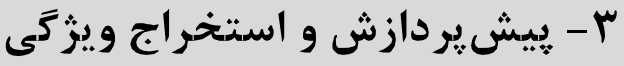

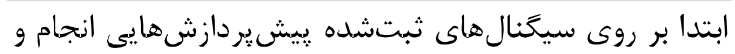

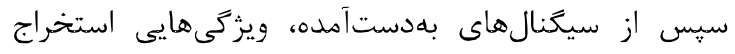
شد. اين دو مرحله در ادامه توضيح داده شده است وديت

$$
\text { ا -r-بيش بيردازش }
$$

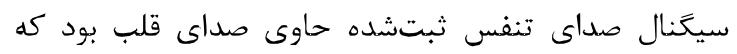
بايد حذف مىشد. با توجه به اين كه فركانس غن غالب صداى صداى 


$$
E D_{i j}=\frac{\sqrt{\begin{array}{l}
\left(F E_{i j R}-F E_{i j L}\right)^{2}+ \\
\left(F M_{i j R}-F M_{i j L}\right)^{2}+ \\
\left(F L_{i j R}-F L_{i j L}\right)^{2}
\end{array}}}{3}
$$

كه در آن i بيانكر شماره شخص، ز زبيانكر شماره ويزگى،

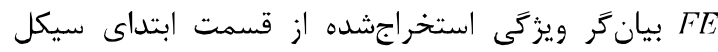

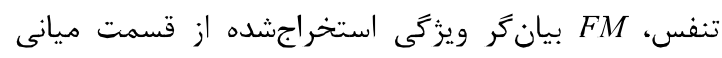
سيكل تنفس و FL بيانكر ويزگكى استخراجشده از قسمت

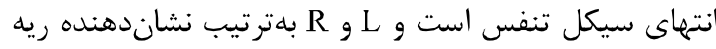
جֶٍ و ريه راست هستند. كه بيانكر تقارن اطلاعات بين ريه راست و ريه

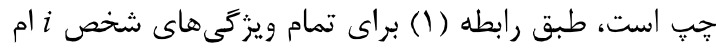

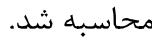

\section{F - انتخاب ويز كى و طبقهبندى}

در اين مرحله بايد بهترين ويزگى ها از بين يانزده ويزگى ذكرشده، انتخاب شده و سيس طبقهيندى شوند. در ادامه اين دو قسمت توضيح داده شده است:

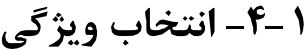

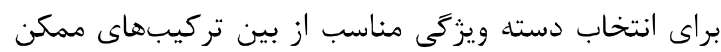

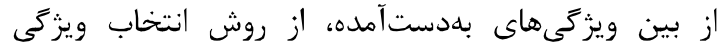
مبتنى بر الكوريتم زنتيك استفاده شد [26]. در اين مرحله

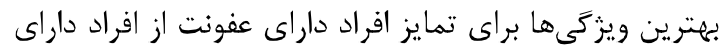
كشت منفى و يس از درمان انتخاب شدند. روش انتخاب ويزكى كه در اين يزوهش استفاده شد، بهصورت زير عمل بل مى كند: • انتخاب جمعيت اوليه بلهصورت تصادفى: در اين مرحله

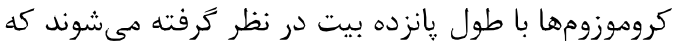
بلهورت تصادفى اين بيتها مى توانند صفر يا يك باشند،

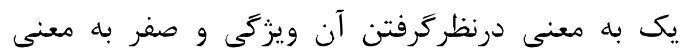
درنظرنكرفتن آن ويزگى است. بهعنوان نمونه براى يكى از كروموزومهايى كد بهصورت تصادفى در مرحله نخست انتخاب شده، بيت لا، هو ل ل يك و ساير بيتها صفر است،

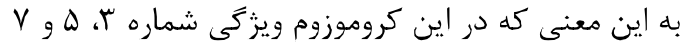
انتخاب شده است • محاسبه مقدار تابع هزينه براى هر يك از افراد. در اين يروهش، تابع هزينه CostF بهصورت رابطه (r) درنظر كرفته شد.
زيرنمودار طيف توان سيخنال به درصد مشخصى از كل سطح

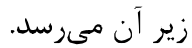

دسته ويزگى سوم، ويزگى هاى آمارى مرتبه بالا

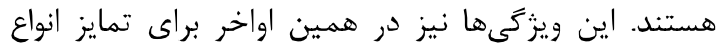
صداهاى تنفس اضافى استفاده شده است [25]. در اين اين مطالعه آماركان مرتبه نخست تا جهارم سيخنال بهعنوان دسته ويزگكى سوم استفاده شدهاند.

(جدول-r): ليست ويزَّى هاى استخراج شده

(Table-2): List of extracted features

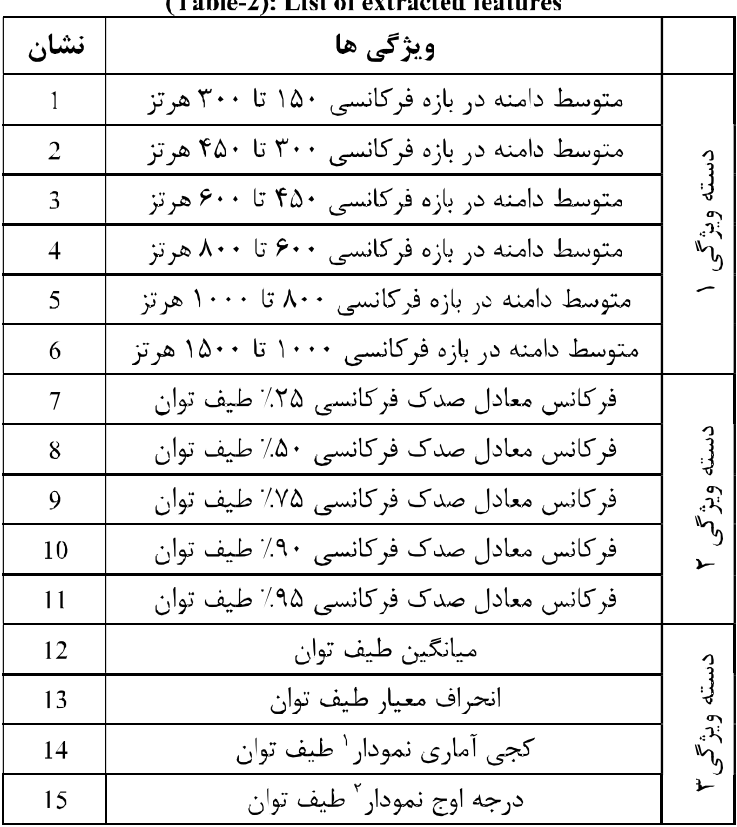

براى بررسى تقارن هر كدام از ويزَّىها بين ريه راست و حِّ از الكَريتمى بهصورت زير استفاده شد.

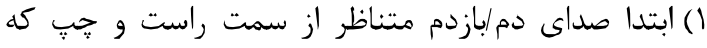
براى هر شخص ثبت شده بودند، به سه قسمت ابتداي سيكل تنفس E ميانه سيكل تنفس M و و انتهاى سيكل تنفس L تقسيم شدند.

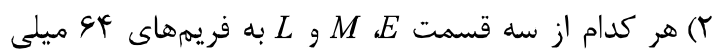

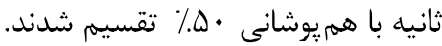
ك) براى هر قاب تمام ويزگ هى هايى كه در قسمت قبل توضيح داده شدند، بلددست آورده شد.

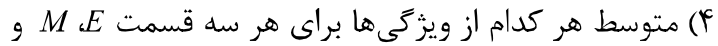
L L بهدست آورده شد. ه) ويزگكىهاى نهايى براى هر فرد براساس رابطه (1) بهدست

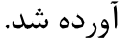

1 Skewness

${ }^{2}$ Kurtosis 
براى طبقهبندى ويزگى هاى انتخابشده سه طبقهبند

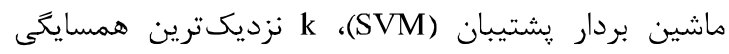

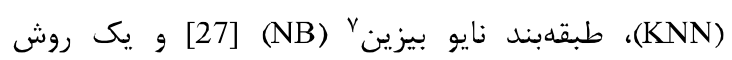
تركيب طبقهبندها مورد استفاده قرار كرفتند.

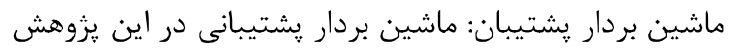

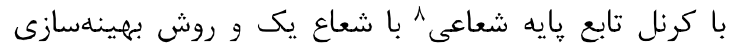

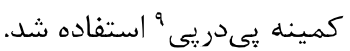
نزديكترين همسايگى: طبقهبند k نزديكترين همسايگى

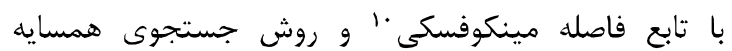

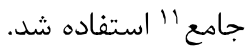
نايو بيزين: اين روش يك نمونه را به گروهى نسبت مى ندهد

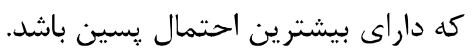

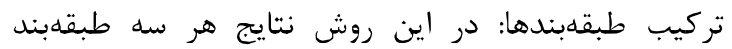

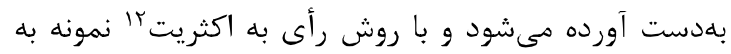

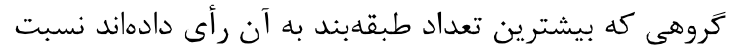
داده مىشود [25, 28, 29.

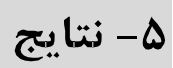
يس از اعمال يِيش هيردازشهاى لازم بر سيخنال هاى تنفس

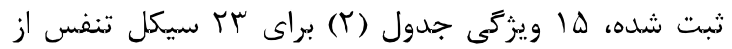

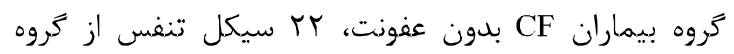
بيماران CF داراى عفونت و إن سيكل تنفس از كروه بيماران CF درمانشده بهدست آورده و سيس براي انتخاب

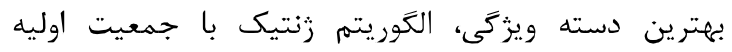

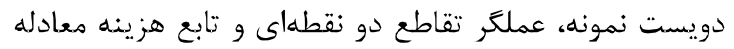

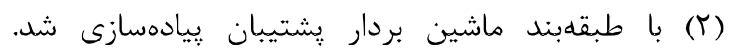

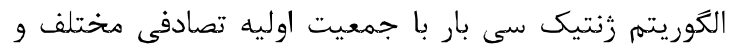
درصد تقاطع متفاوت اجرا شد.

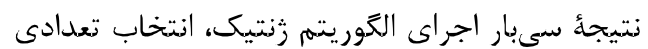

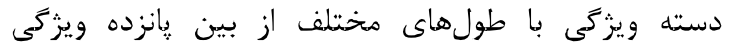

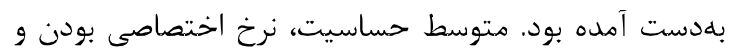
صحت طبقهبندى بين دو گروه بيمار CF بدون عفونت و

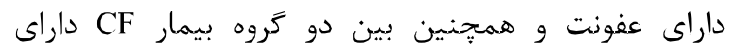

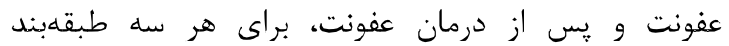
مطرحشده در قسمت قبل (طبقهبند SVM و SBN، KNN) و همهنين تركيب طبقهبندها بهترتيب براى صداى دم و بازدم

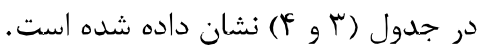

\footnotetext{
${ }^{7}$ Naïve Bayesian

${ }^{8}$ Radial Basis Function

${ }^{9}$ Sequential Minimal Optimization

${ }^{10}$ Minkowski

${ }^{11}$ Exhaustive

${ }^{12}$ Majority Voting
}

$\sqrt{\frac{\operatorname{Cost} F=0.05 L f}{(1-\operatorname{sen} s)^{2}+(1-\operatorname{spec} 1)^{2}}}+$

كه در آن خارامترها بهصورت زير تعريف مىشوند: Sens1 O اختصاصىبودن ' در تشخيص افراد داراى كشت مثبت حاصل از طبقهبندى بين دو كروه كشت مثبت و كشت درد

$$
\text { منفى است. }
$$

Sens2 و spec2 بهترتيب حساسيت و نرخ اختصاصىبودن در تشخيص افراد داراى كشت مثبت حاصل از طبقهبندى

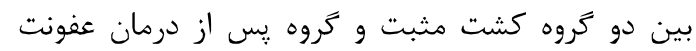
است.

LFO

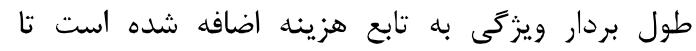

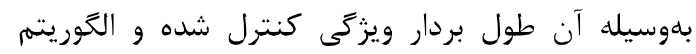

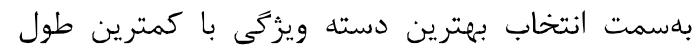

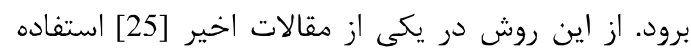

• انتخاب ب بهترين افراد از جمعيت كه داراى كمترين مقدار

$$
\begin{aligned}
& \text { تابع هزينه هستند؛ }
\end{aligned}
$$

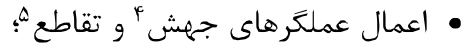

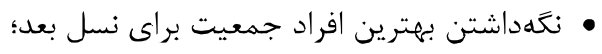

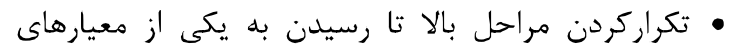

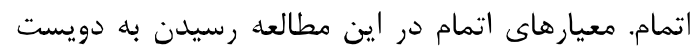

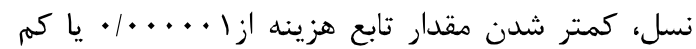

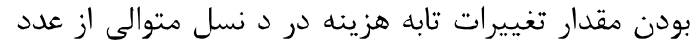

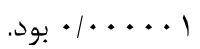

\section{r-r-r}

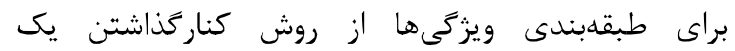
شركتكنندهء استفاده شد. به اين معنى كله در هر هر مرحله ويزگَىهاى مربوط به يك نفر براى ارزيابى طبقهبند كنار

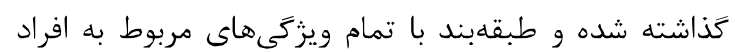

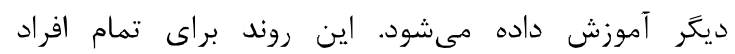

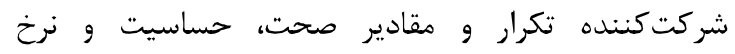
اختصاصىبودن براساس نتيجه بهدستآمده براى تمام افراد

محاسبه ميىشود.

${ }^{1}$ Sensitivity
${ }^{2}$ Specificity
${ }^{3}$ Selection
${ }^{4}$ Mutation
${ }^{5}$ Crossover
${ }^{6}$ Leave one subject out




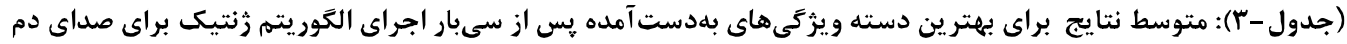

(Table-3): Average results for selected group of features from inspiration sound after 30 times running of genetic algorithm

\begin{tabular}{|c|c|c|c|c|c|c|}
\hline \multicolumn{3}{|c|}{ دو كروه بيمار CF داراى عفونت و يس از درمان عفونت } & \multicolumn{3}{|c|}{ دو كروه بيمار CF بدون عفونت و داراى عفونت } & \multirow[b]{2}{*}{ طبقهبندى كننده } \\
\hline صحت & نرخ اختصاصىبودن & حساسيت & صحت & نرخ اختصاصىبودن & حساسيت & \\
\hline $87.3-3.9$ & $85.4 \perp 5.7$ & $89.0 \perp 5.1$ & $81.7 \perp 3.1$ & $85.0 \perp 5.1$ & $78.2 \perp 5.7$ & SVM \\
\hline $70.9=8.8$ & $76.9 \pm 4.6$ & $64.8 \pm 15.0$ & $67.8 \pm 13.6$ & $68.8 \pm 10.0$ & $66.6=10.6$ & KNN \\
\hline $56.1=6.5$ & $50.3 \pm 4.6$ & $61.8 \pm 9.2$ & $74.5 \pm 8.9$ & $65.5 \pm 6.1$ & $82.4=15.6$ & $\mathrm{NB}$ \\
\hline $91.2 \pm 3.1$ & $93.3 \pm 4.1$ & $89.0 \pm 5.1$ & $95.1 \pm 2.2$ & $96.1 \pm 4.3$ & $93.9 \pm 7.4$ & تركيب طبقهبندها \\
\hline
\end{tabular}

(جدول - (F): متوسط نتايج براى بهترين دسته ويثَى هاى بهدست آمده پيس از سىبار اجراى الكور يتم زنتيك براى صداى بازدم

(Table-4): Average results for selected group of features from expiration sound after 30 times running of genetic algorithm

\begin{tabular}{|c|c|c|c|c|c|c|}
\hline \multicolumn{3}{|c|}{ دو تروه بيمار CF داراى عفونت و يس از درمان عفونت } & \multicolumn{3}{|c|}{ دو كروه بيمار CF بدون عفونت و داراى عفونت } & \multirow[b]{2}{*}{ طبقهبندى كننده } \\
\hline صحت & نرخ اختصاصى بودن & حساسيت & صحت & نرخ اختصاصىبودن & حساسيت & \\
\hline $64.8 \pm 3.2$ & $77.5 \pm 10.2$ & $52.1=14.1$ & $71.0 \pm 7.1$ & $81.6 \pm 5.1$ & $59.4 \pm 15.6$ & SVM \\
\hline $65.4 \perp 7.1$ & $75.7 \perp 4.4$ & $55.1-11.1$ & $81.4 \perp 6.2$ & $90.5 \perp 2.9$ & $71.6 \perp 12.6$ & KNN \\
\hline $56.9 \pm 2.3$ & $64.3 \pm 9.3$ & $49.8 \pm 4.2$ & $68.7 \pm 4.1$ & $82.7 \pm 10.1$ & $53.3 \pm 12.3$ & NB \\
\hline $78.2 \pm 11.1$ & $83.3 \pm 10.1$ & $73.3 \pm 11.1$ & $93.36 \pm 2.2$ & $98.8 \pm 2.9$ & $87.9 \pm 4.4$ & تركيب طبقدبندها \\
\hline
\end{tabular}

تركيب طبقلبندها منجر به بهترين نتيجه شده و به صحت

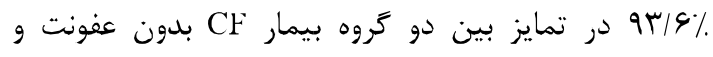

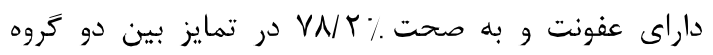
بيمار CF داراى عفونت و يس از درمان عفونت شده است.

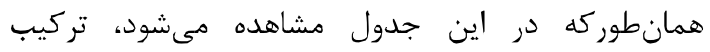

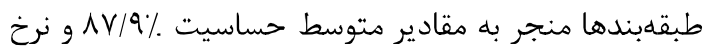
اختصاصى بودن \% 91/1 در تشخيص عفونت و همجنين

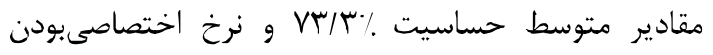

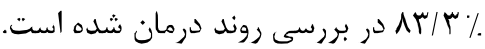

نتايج بهترين دسته ويزگى از بين دفعات مختلف اجراى الكوريتم زنتيك، در جدول (ه) نشان داده شده است.
در مقايسه بين سه طبقهبند در جدول (r) كه

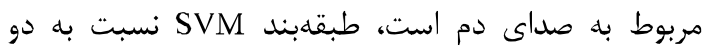
طبقهبند ديكر منجر به نتايج بهترى شده است. نتايج كلى دم براى تركيب طبقهبندها بهتر از هر كدام از طبقهبندها بهصورت جداكانه شده و به صحت / \% 9 در تمايز بين دو كروه بيمار CF بدون عفونت و داراى عفونت و به صحت

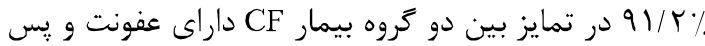
از درمان عفونت رسيده است. همانطوركه در اين جدول مشاهده مىشود، تركيب طبقهبندها منجر به مقادير متوسط

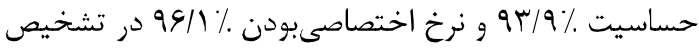

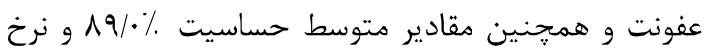
اختصاصىبودن \% \% است. در جدول (f) كه مربوط به صداى بازدم است نيز

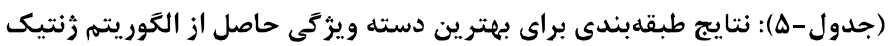

(Table-5): Classification results for the best selected feature groups which were obtained by applying genetic algorithm

\begin{tabular}{|c|c|c|c|c|c|c|}
\hline \multicolumn{3}{|c|}{ دو Fروه بيمار CF داراى عفونت و يس از درمان عفونت } & \multicolumn{3}{|c|}{ دو كروه بيمار CF بدون عفونت و داراى عفونت } & \multirow[b]{2}{*}{ طبقهبندى كننده } \\
\hline صحت & نرخ اختصاصىبودن & حساسيت & صحت & نرخ اختصاصىبودن & حساسيت & \\
\hline \multicolumn{7}{|c|}{ بهترين كروه ويزگكى انتخاب شده از صداى دم: 1, 4, 7, 8, 11, 12} \\
\hline 90.9 & 90.9 & 90.9 & 86.9 & 100 & 72.8 & SVM \\
\hline 90.9 & 90.9 & 90.9 & 91.3 & 100 & 81.8 & تركيب طبقهبندها \\
\hline \multicolumn{7}{|c|}{ بهترين كروه ويزُكى انتخاب شده از صداى بازدم: 1,3,13 } \\
\hline 72.7 & 63.6 & 81.8 & 86.9 & 91.6 & 81.8 & SVM \\
\hline 86.3 & 81.8 & 90.9 & 91.3 & 91.6 & 90.9 & تركيب طبقهبندها \\
\hline
\end{tabular}

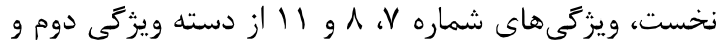

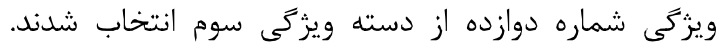

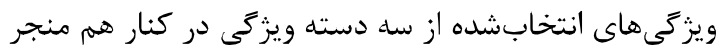
به نتايج مطلوبى در تشخيص عفونت شدند. اگر هركدام از
همانطوركه در اين جدول ديده ميشود، بهترين

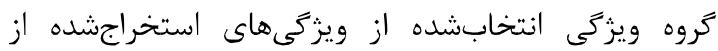

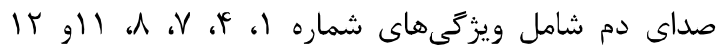
است كه ويزگ 


\section{9- نتيجه گيرى و بيشنهيادها}

همانطوركه بيان شد، در اين مطالعه براى نخستينبار از صداى تنفس بيماران CF براى تشخيص عفونت و همجنين تشخيص موفقيت درمان عفونت در اين بيماران استفاده شده

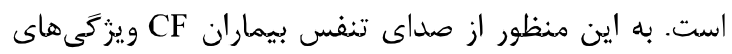
فركانسى مختلفى استخراج و تقارن اطلاعات فركانسى ريه

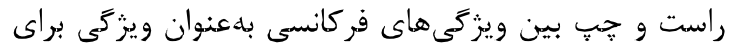

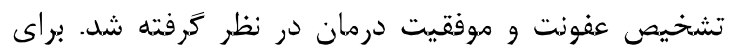
طبقهبندى جهت تشخيص عفونت و موفقيت درمان، از سه

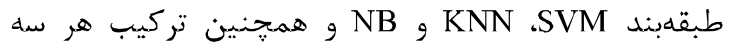

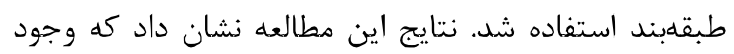

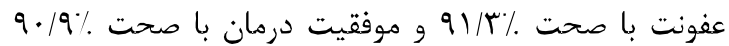
قابل تشخيص است. خلاصٔ زتايج اين يزوهش به شرح زير •بهترين نتايج توسط تركيب طبقهبندها بهدست آهد.

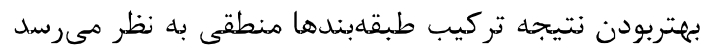

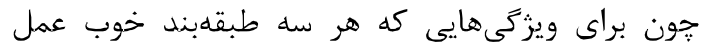

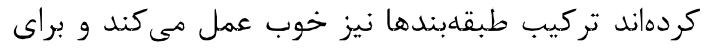

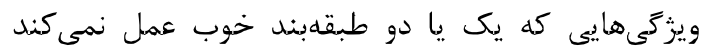
نتايج ساير طبقهبندها باعث بهبود نتيجه كلى مى شود. • نتايج نشان داد كه صداى دم و بازدم در تشخيص عفونت

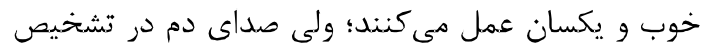
موفقيت درمان عملكرد بهترى دارد.

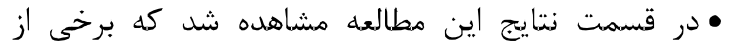

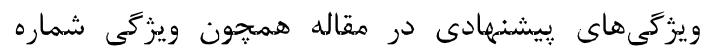
جهار و يازده براى تشخيص عفونت و موفقيت درمان بهصورت تكى خوب عمل مى كنند. ويزَّى شمارة حهبهار، متوسط دامنه صداى تنفس در بازه فركانسى ششصد تاب

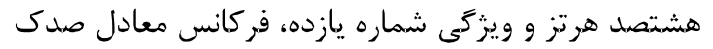
فركانسى هو٪ طيف توان است. همانطوركه درقبل بيان

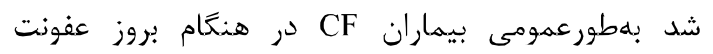
سودوموناس افزايش خلط و افزايش صداى اضافى ريه و

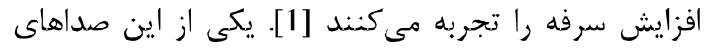
اضافى كه در ريه بيماران CF اضافه مىشود، صداى كراكل است كه در اثر باز و بستهشدن ناكميانى راههاى هوايى شنيده مىشود و فركانس آن در حدود • •9 هرتز است

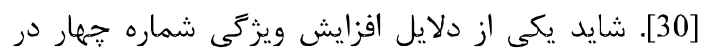

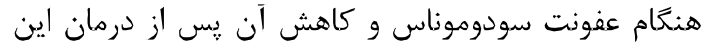
عفونت، بهعلت ظهور صداى اضافى كراكل و ازبينرفتن آن آن آن آن آن
ويزگى ها بلهورت جداكانه در نظر كرفته شوند، در تمام

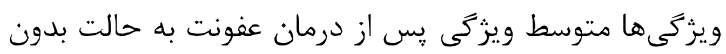

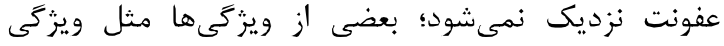

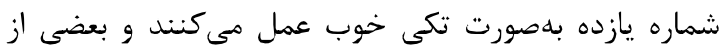

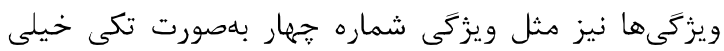

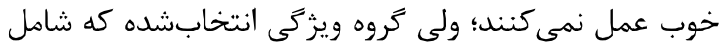

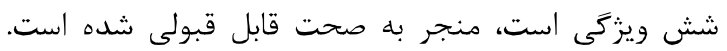

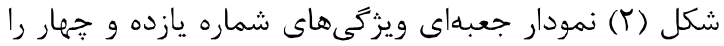

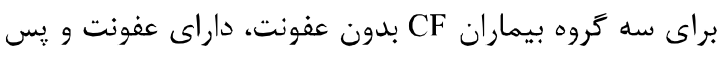
از درمان عفونت نشان مى دهد.
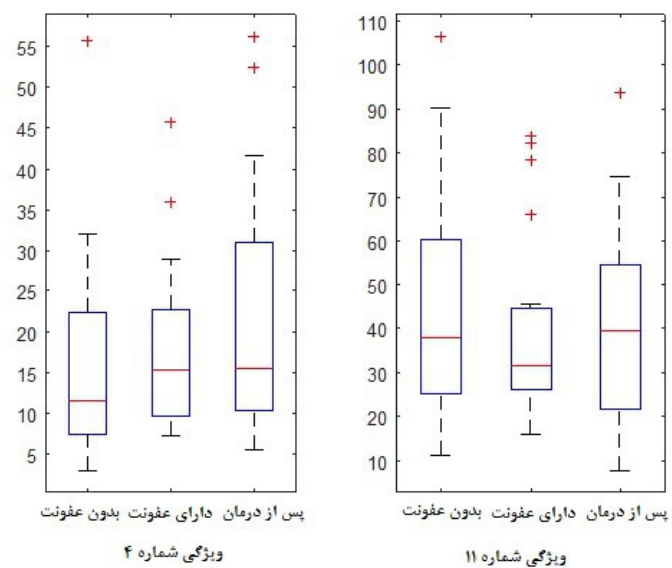

(شكل -r): نمودار جعبهاى براى ويزكى هاى شماره جهار و يازده. (Figure-2): Boxplot for features of number 4 and 11.

همانطور كه در شكل (T) ديده مىشود، ويزَى

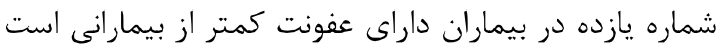

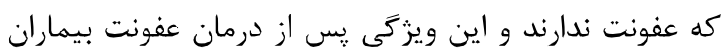

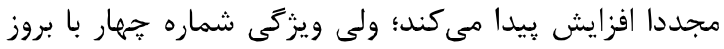
عفونت، زيادتر شده، ولى يس از درمان عفونت تغيير جندانى

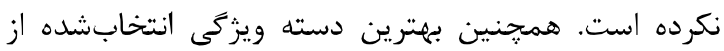
ويزگى هاى استخراجشده از صداى بازدم شامل ويزَّى هاى

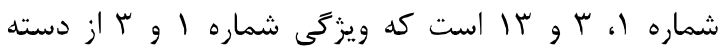

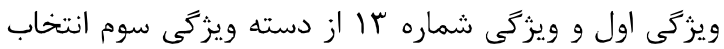

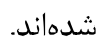

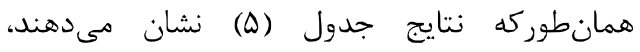
ويزگى هاى استخراجشده از صداى دم و صداى بازدم صحت

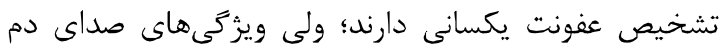
صحت بالاترى در تشخيص موفقيت درمان عفونت نسبت بهان

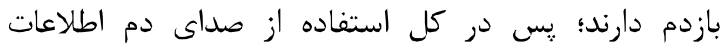

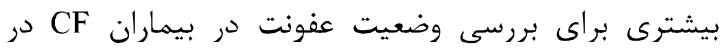

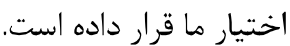


مطالعه كنونى با تعداد كمتر ويثزَى نسبت به مطالعات قبلى (شش ويزگى براى صداى دم و سه ويزگى براى صداى

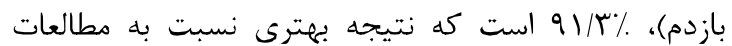

\section{7- References}

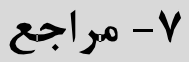

[1] M. A. Koda-Kimble, Koda-Kimble and Young's applied therapeutics: the clinical use of drugs: Lippincott Williams \& Wilkins, 2012.

[2] M. modaresi, J. faghihinia, and F baharzadeh, "Cystic Fibrosis Prevalence among a Group of High-Risk Iranian Children ",Journal of Isfahan

Medical School, vol. 30, 2012.

[3] N. Pillarisetti, E. Williamson, B. Linnane, B. Skoric, C. F. Robertson, P. Robinson, J. Massic, G. L. Hall, P. Sly, and S. Stick, "Infection, inflammation, and lung function decline in infants with cystic fibrosis," American journal of respiratory and critical care medicine, vol. 184, pp. 75-81, 2011.

[4] H. G. Ahlgren, A. Benedetti, J. S. Landry, J. Bernier, E. Matouk, D. Radzioch, L. C. Lands, S. Rousseau, and D. Nguyen, "Clinical outcomes associated with Staphylococcus aurcus and Pseudomonas aeruginosa airway infections in adult cystic fibrosis patients," BMC pulmonary medicine, vol. 15, pp. 67, 2015.

[5] Z. Li, M. R. Kosorok, P. M. Farrell, A. Laxova, S. E. West, C. G. Green, J. Collins, M. J. Rock, and M. L. Splaingard, "Longitudinal development of mucoid Pseudomonas aeruginosa infection and lung disease progression in children with cystic fibrosis," Jama, vol. 293, pp. 581-588, 2005.

[6] K. M. Langan, T. Kotsimbos, and A. Y. Peleg, "Managing Pscudomonas acruginosa respiratory infections in cystic fibrosis," Current opinion in infectious diseases, vol. 28, pp. 547-556, 2015.

[7] P. J. Mogayzel Jr, E. T. Naureckas, K. A. Robinson, C. Brady, M. Guill, T. Lahiri, L. Lubsch, J. Matsui, C. M. Oermann ,and F. Ratjen, "Cystic Fibrosis Foundation pulmonary guideline. Pharmacologic approaches to prevention and eradication of initial Pseudomonas aeruginosa infection," Annals of the American Thoracic Society, vol. 11, pp. 1640-1650, 2014.

[8] A. R. Smyth ,S. C. Bell, S. Bojcin, M. Bryon, A. Duff, P. Flume, N. Kashirskaya, A. Munck, F. Ratjen, and S. J. Schwarzenberg, "European cystic

$$
\begin{aligned}
& \text { باشد. در مورد كاهش مقدار ويزگى شماره يازده در هنگام }
\end{aligned}
$$

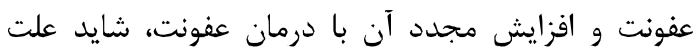

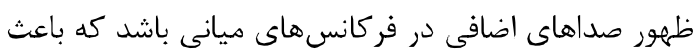

$$
\begin{aligned}
& \text { مىشود قسمت بيشترى از محتواى فركانسى صداى }
\end{aligned}
$$

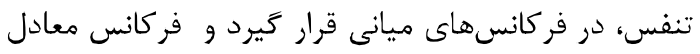

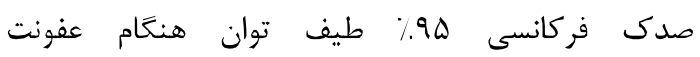

$$
\begin{aligned}
& \text { سودوموناس كاهش يیيدا كند. }
\end{aligned}
$$

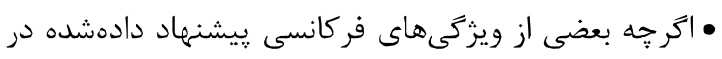

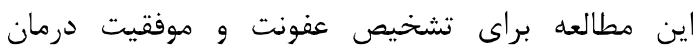

$$
\begin{aligned}
& \text { بهصورت تكى خوب عمل مى كنند، ولى همه ويزَّى ها } \\
& \text { بهصورت تكى خوب عمل نمى كنند. با اين حال كروه } \\
& \text { انتخابشده حاوى جند ويزگى كنار هم منجر بله نتايج } \\
& \text { مطلوبى شد. }
\end{aligned}
$$

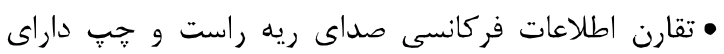

$$
\begin{aligned}
& \text { رابطه منطقى با عفونت در بيماران CF است. }
\end{aligned}
$$

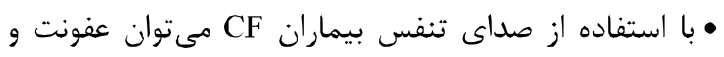

$$
\begin{aligned}
& \text { موفقيت درمان عفونت در اين بيماران را تشخيص دادي داد. بـان } \\
& \text { مطالعه كنونى نشان داد كه رابطه منطقى بين عفونت } \\
& \text { در ريه بيماران CF و صداى تنفس آنها وجود دارد. نتايج } \\
& \text { وجود عفونت را با صحت خوبى از اطلاعات صداى تنفس }
\end{aligned}
$$

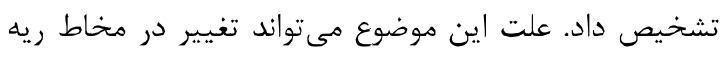

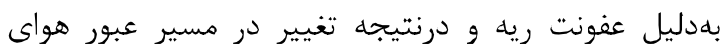

$$
\begin{aligned}
& \text { داخل ريه باشد كه منجر به عوضشدن صداى تنفس } \\
& \text { مى شود. } \\
& \text { با استفاده از صداى تنفس كه روشى آسان است } \\
& \text { مىتوان وضعيت ريه افراد CF را بررسى كرد. همجنين امكان } \\
& \text { استفاده از اطلاعات صداى تنفس در تشخيص عفونت } \\
& \text { سودوموناس وجود دارد و مى تواند در كنار روشهاى ديخر } \\
& \text { به كمك يزشك متخصص بيايد. } \\
& \text { تاكنون كار مشابهى براى تشخيص عفونت از صداى }
\end{aligned}
$$

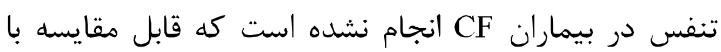

$$
\begin{aligned}
& \text { اين مطالعه باشد، تنها كارهاى بهطورتقريبى نزديك به اين }
\end{aligned}
$$

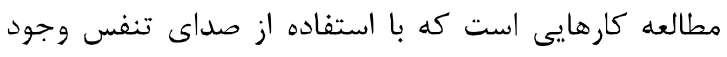

$$
\begin{aligned}
& \text { خلط را تشخيص دادهاند. در سال IV V • ميلادى تشخيص } \\
& \text { افزايش خلط بيماران با استفاده از صداى تنفس دوازده نفر }
\end{aligned}
$$

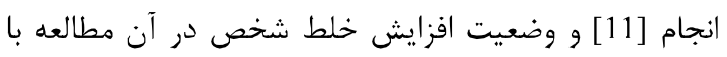

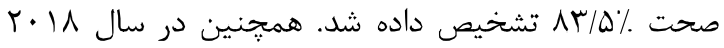

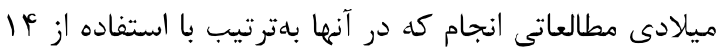

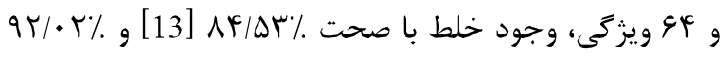

$$
\begin{aligned}
& \text { [12] تشخيص داده شده است. صحت تشخيص عفونت درد }
\end{aligned}
$$


[18] R. P. Dellinger, J. E. Parrillo, A. Kushnir, M. Rossi, and I. Kushnir, "Dynamic visualization of lung sounds with a vibration response device: a case series," Respiration, vol. 75, pp. 60-72, 2008.

[19] A. Torres-Jimenez, S. Charleston-Villalobos, R. Gonzalez-Camarena, G. Chi-Lem, and T. Aljama-Corrales, "Asymmetry in lung sound intensities detected by respiratory acoustic thoracic imaging (RATHI) and clinical pulmonary auscultation," in Enginecring in Medicine and Biology Society, 2008. EMBS $2 \mu \cdot$. . 1th Annual International Conference of the IEEE, 2008, pp. 4797-4800.

[20] J. Gnitecki and Z. M. Moussavi, "Separating heart sounds from lung sounds," IEEE Engineering in medicine and biology magazine, vol. 26, pp. 20, 2007.

[21] D. S. Morillo, S. A .Moreno, M. Á. F. Grancro, and A. L. Jiménez, "Computerized analysis of respiratory sounds during COPD exacerbations," Computers in biology and medicine, vol. 43, pp. 914-921, 2013.

[22] M. Tenhunen, E. Rauhala, E. Huupponen, A. Saastamoinen, A. Kulkas, and S. Himanen, "High frequency components of tracheal sound are emphasized during prolonged flow limitation," Physiological measurement, vol. 30, pp. $467,2009$.

[23] S. Charleston-Villalobos, L. Albuerne-Sanchez, R. Gonzalez-Camarena, M. Mejia-Avila, G. Carrillo-Rodriguez, and T. Aljama-Corrales, "Lincar and nonlinear analysis of base lung sound in extrinsic allergic alveolitis patients in comparison to healthy subjects," Methods of information in medicine, vol. 52, pp. 266-276, 2013.

[24] V. Rocha, C. Mclo, and A. Marques, "Computerized respiratory sound analysis in people with dementia: a first-step towards diagnosis and monitoring of respiratory conditions," Physiological measurement, vol. 37, pp. 2079, 2016.

[25] R. Naves, B. H. Barbosa, and D. D. Ferreira, "Classification of lung sounds using higherorder statistics: A divide-and-conquer approach," Computer methods and programs in biomedicine, vol. 129, pp. 12-20, 2016.

[26] O. Kramer, Genetic algorithm essentials vol. 679: Springer, 2017. fibrosis socicty standards of carc: best practice guidelines," Journal of cystic fibrosis, vol. 13, pp. S23-S42, 2014.

[9] S .Ferrari, M. Silva, M. Guarino, J. M. Aerts, and D. Berckmans, "Cough sound analysis to identify respiratory infection in pigs," Computers and Electronics in Agriculture, vol. 64, pp. 318-325, 2008.

[10] A. Oliveira, C. Pinho, J. Dinis, D. Oliveira, and A. Marques, "Automatic Whecze Detection and Lung Function Evaluation-A Preliminary Study," in HEALTHINF, 2013, pp. 323-326.

[11] J. Niu, Y. Shi, M. Cai, Z. Cao, D. Wang, Z. Zhang, and X. D. Zhang, "Detection of sputum by interpreting the time-frequency distribution of respiratory sound signal using image processing techniques," Bioinformatics, vol. 34, pp. 820-827, 2017.

[12] J. Niu, Y. Shi, D. Shen, Y. Wang, W. Xu, M. Cai, and Y. Li, "The Identification of Sputum Situation Based on the Sound from the Respiratory Tract," in 2018 IEEE/ASME International Conference on Advanced Intelligent Mechatronics (AIM), 2018, pp. 11661171 .

[13] Y. Shi, G. Wang, J. Niu, Q. Zhang, M. Cai, B. Sun, D. Wang, M. Xue, and X. D. Zhang, "Classification of sputum sounds using artificial neural network and wavelet transform," Int. J. Biol. Sci, 2018.

[14] W. L. Wilkins, "Auscultation skills: breath and heart sounds," Auscultation Skills: Breath and Heart Sounds, pp. 156-157, 2009.

[15] R. Dosani and S. Kraman, "Lung sound intensity variability in normal men: a contour phonopneumographic study," Chest, vol. 83, pp. 628-631, 1983.

[16] H. Pasterkamp, S. Patel, and G. Wodicka, "Asymmetry of respiratory sounds and thoracic transmission," Medical and Biological Engineering and Computing, vol. 35, pp. 103-106, 1997.

[17] Z. K. Moussavi, M. T. Leopando, H. Pasterkamp, and G. Rempel, "Computerised acoustical respiratory phase detection without airflow measurement," Medical and Biological Engineering and Computing, vol. 38, pp. 198203, 2000. 


$$
\begin{aligned}
& \text { كارى مورد علاقه وى يردازش دادكان يزشكى، پردازش }
\end{aligned}
$$

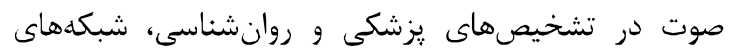

$$
\begin{aligned}
& \text { عصبى مصنوعى است. } \\
& \text { نشانى رايانامة ايشان عبارت است از: }
\end{aligned}
$$

mansour.vali@eetd.kntu.ac.ir

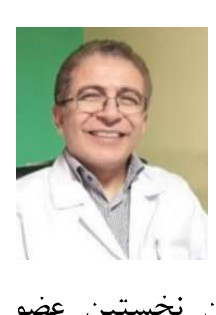

محمدرضا مدرسى تحصيلات خود را در

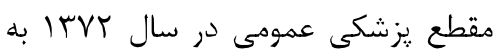

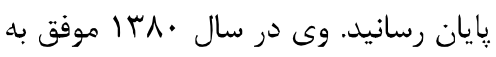

اخذ بورد تخصصى كودكان و در دانشكاه

علوم يزشكى اصفهان بهعنوان عضو هيئت

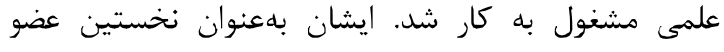

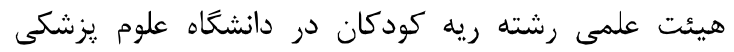

تهران مشغول به كار شد و مسئوليت راهاندازى و توسعه

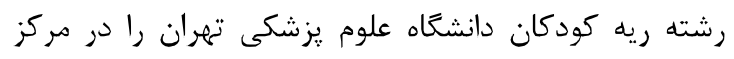

طبى كودكان به عهده كرفت. وى هم اكنون عضو هيئت

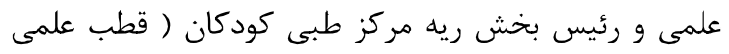

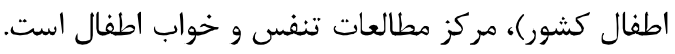

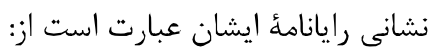

\section{mr-modaresi@sina.tums.ac.ir}

[27] X. Wu ,V. Kumar, J. R. Quinlan, J. Ghosh, Q. Yang, H. Motoda, G. J. McLachlan, A. Ng, B. Liu, and S. Y. Philip, "Top 10 algorithms in data mining," Knowledge and information systems, vol. 14, pp. 1-37, 2008.

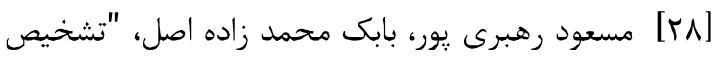

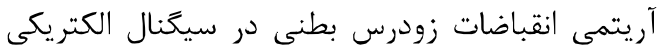

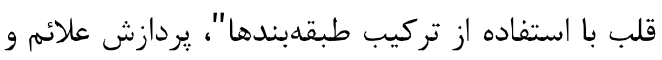

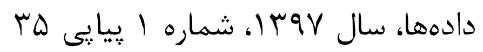

[28] M. Rahbaripour and B. M. Asl, "Premature Ventricular Contraction Arrythmia Detection in ECG Signals via Combined Classifiers," Signal and Data Processing, vol. 1, 2018.

[29] L. I. Kuncheva, J. C. Bezdek, and R. P. Duin, "Decision templates for multiple classifier fusion: an experimental comparison," Pattern recognition, vol. 34, pp. 299-314, 2001.

[30] A. Bohadana, G. Izbicki, and S. S. Kraman, "Fundamentals of lung auscultation," New England Journal of Medicine, vol. 370, pp. 744751, 2014.

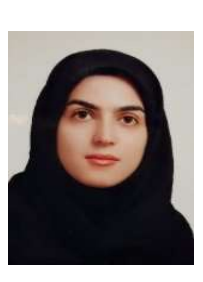
آرزو كريمىزاده در سال

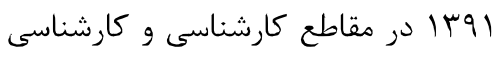

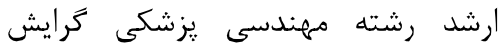

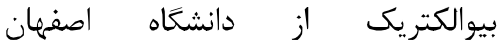
فارغالتحصيل شد. وى هماكنون دانشجوى دئري مقطع دكتراى برق- بيوالكتريك در دانشعاه صنعتى خواجه

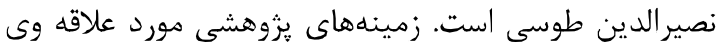

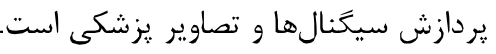

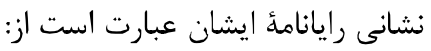
a.karimizadeh@ee.kntu.ac.ir

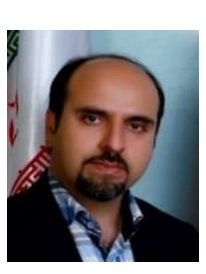

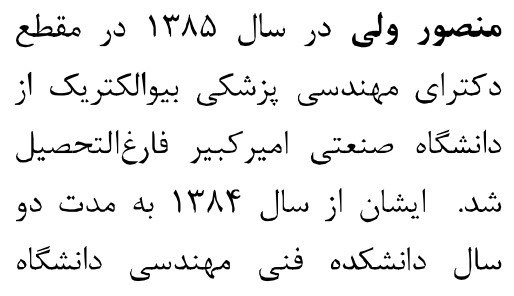

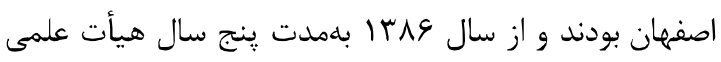

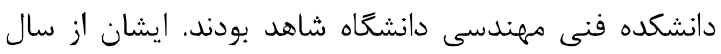

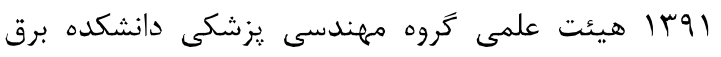

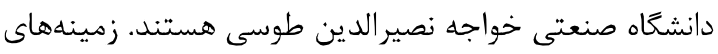


